\title{
Effective Absorption Cross Sections and Photolysis Rates of Anthropogenic and Biogenic Secondary Organic Aerosols
}

Dian E. Romonosky, Nujhat N. Ali, Mariyah N. Saiduddin, Michael Wu, Hyun Ji (Julie) Lee, Paige K. Aiona and Sergey A. Nizkorodov*

Department of Chemistry, University of California, Irvine, California 92697, USA.

* Corresponding author phone and e-mail: 949-824-1262, nizkorod@uci.edu

\begin{abstract}
Mass absorption coefficient (MAC) values were measured for secondary organic aerosol (SOA) samples produced by flow tube ozonolysis and smog chamber photooxidation of a wide range of volatile organic compounds (VOC), specifically: $\alpha$-pinene, $\beta$-pinene, $\beta$ myrcene, d-limonene, farnesene, guaiacol, imidazole, isoprene, linalool, ocimene, $\mathrm{p}$-xylene, 1-methylpyrrole, and 2-methylpyrrole. Both low- $\mathrm{NO}_{\mathrm{x}}$ and high- $\mathrm{NO}_{\mathrm{x}}$ conditions were employed during the chamber photooxidation experiments. MAC values were converted into effective molecular absorption cross sections assuming an average molecular weight of 300 $\mathrm{g} / \mathrm{mol}$ for SOA compounds. The upper limits for the effective photolysis rates of SOA compounds were calculated by assuming unity photolysis quantum yields and convoluting the absorption cross sections with a time-dependent solar spectral flux. A more realistic estimate for the photolysis rates relying on the quantum yield of acetone was also obtained. The results show that condensed-phase photolysis of SOA compounds can potentially occur with effective lifetimes ranging from minutes to days, suggesting that photolysis is an efficient and largely overlooked mechanism of SOA aging.
\end{abstract}

Keywords: secondary organic aerosol; mass absorption coefficient; photolysis rate; atmospheric photochemistry; photodegradation 


\section{INTRODUCTION}

Primary organic aerosol (POA) directly emitted from anthropogenic and biogenic sources and secondary organic aerosol (SOA) produced by gas-phase or aqueous-phase oxidation of atmospheric volatile organic compounds (VOC) have both health and climate relevance (Ervens et al., 2011; Finlayson-Pitts and Pitts, 2000; Solomon et al., 2007). Biogenic VOC that contribute the most to SOA production include isoprene, $\alpha$-pinene, $\beta$ pinene, myrcene, and limonene (Geron et al., 2000). In urban areas, major sources of VOC are from fossil fuel combustion as well as industrial emissions (World Health, 1989). Once in the atmosphere, organic aerosol (OA) is known to undergo both physical and chemical aging processes from reactions with sunlight and atmospheric oxidants (George et al., 2015). It is important to understand the nature of these changes in order to predict the health and climate impacts of atmospheric aerosols that travel long distances from the point of their initial formation.

Prevalent chemical mechanisms for OA aging involve multiphase oxidation of OA constituents by atmospheric oxidants. The most dominant oxidant involved in the multiphase oxidation of OA, as well as aqueous-phase oxidation of water-soluble atmospheric organics, is the $\mathrm{OH}$ radical (Ervens et al., 2011; George et al., 2015). $\mathrm{NO}_{3}, \mathrm{O}_{3}$, and other oxidants also contribute to these aging processes. OA compounds can additionally be aged by condensedphase photochemical reactions occurring in the bulk of the SOA material upon exposure to solar actinic radiation (George et al., 2015). Currently, experimental evidence to determine the relative importance of condensed-phase photochemistry occurring in OA relative to multi-phase oxidation processes is limited. Chamber studies have begun to examine this effect by studying the properties and composition of SOA before and after exposure to UV light. Presto et al. (2005) found that the formation of $\alpha$-pinene ozonolysis SOA in a smog chamber was suppressed by $20-40 \%$ when exposed to UV light. Kroll et al. (2006) observed that low- $\mathrm{NO}_{\mathrm{x}}$ isoprene $\mathrm{SOA}$ grew during the initial irradiation period, but that was followed by a decrease in particle size as the SOA mixture was further irradiated. However, $\beta$-pinene low- $\mathrm{NO}_{\mathrm{x}}$ SOA particles did not shrink upon irradiation, indicating that the photochemical effects of UV exposure are dependent on the chemical composition of the SOA. Surratt et al. (2006) detected a similar decrease in the particle size of low- $\mathrm{NO}_{\mathrm{x}}$ isoprene SOA upon irradiation. In these experiments, it was difficult to separate the effects of gas-phase and condensed-phase photochemistry. To bypass this limitation, Epstein et al. (2014) used a denuder to remove VOC from $\alpha$-pinene ozonolysis SOA before the irradiation. They observed that UV light slightly reduced both the particle mass concentration and the average particle size; the fraction of organic peroxides in the particles decreased upon irradiation. Epstein et al. (2014) and Wong et al. (2014) similarly observed a reduction in the particle size for $\alpha$-pinene ozonolysis SOA material that was collected on a filter and re-aerosolized back in a photolysis chamber; the effect was larger at elevated relative humidity (RH). In contrast, Kourtchev et al. (2015) observed no significant change to molecular level composition of SOA prepared by ozonolysis of a mixture of four biogenic VOC ( $\alpha$-pinene, $\beta$-pinene, $\Delta 3$ carene and isoprene) and exposed to actinic UV radiation. In summary, chamber experiments suggest that photochemical processes in SOA particles are possible, but the results are inconsistent. 
Qualitative experiments with irradiation of bulk SOA samples were carried out by Walser et al. (2007) and Mang et al. (2008). Both studies showed that SOA particles formed from limonene ozonolysis absorbed radiation in the actinic region, most likely due to the carbonyl and peroxide functional groups present, and that the ensuing photochemistry generated a number of small VOC as detectable products. The carbonyl functional groups appeared to play a significant role in this aging, as evidenced by the production of measureable quantities of $\mathrm{CO}, \mathrm{CH}_{4}$, acetaldehyde, acetone, and other $\mathrm{VOC}$, many of which could be explained by standard Norrish type-I and Norrish type-II carbonyl photochemistry (Mang et al., 2008; Pan et al., 2009).

Condensed-phase photochemistry is not limited to the OA particles; it can also take place in cloud/fog droplets. The irradiation of aqueous extracts of limonene ozonolysis SOA resulted in a significant change in the molecular composition, in which oligomeric and carbonyl compounds were depleted (Bateman et al., 2011). The photolytic processing appeared to be more efficient when SOA was dissolved in an aqueous solution as compared to dry SOA particles. The direct aqueous photolysis of high- $\mathrm{NO}_{\mathrm{x}}$ isoprene SOA also produced major changes in the molecular composition (Nguyen et al., 2012). On average, $30 \%$ of the SOA by mass was significantly modified, suggesting that the effects of direct aqueous photolysis should not be ignored. Aqueous solutions of light-absorbing OA compounds, such as SOA formed by photooxidation of naphthalene under high-NOx conditions, SOA formed by limonene ozonolysis and aged with ammonia vapor, and products of aqueous reaction of glyoxal and methylglyoxal with ammonium sulfate were shown to efficiently photobleach and undergo a large change in composition upon exposure to irradiation (Lee et al., 2014; Sareen et al., 2010; Zhao et al., 2015). Finally, a systematic study of photochemistry of different types of SOA by Romonosky et al. (2015) showed that aqueous photolysis may be an effective aging mechanism for SOA derived from biogenic, anthropogenic, and biomass burning VOC precursors.

The experiments done so far have been qualitative in nature; the diversity in structure and reactivity of VOC complicate the scientific understanding of the photochemistry of atmospheric aerosols. To better estimate the time scales of these photochemical processes under realistic atmospheric conditions, this study focuses on the quantitative measurements of absorption coefficients of SOA formed through the oxidation of biogenic and anthropogenic VOC using common atmospheric oxidants, specifically $\mathrm{OH}$ (in presence or absence of $\mathrm{NO}_{\mathrm{x}}$ ) and $\mathrm{O}_{3}$. From these data, the rates of photolysis for a variety of SOA were calculated, resulting in a better understanding of the lifetimes of SOA in the atmosphere with respect to condensed-phase photochemistry.

\section{MATERIALS AND METHODS}

Both $\mathrm{O}_{3}$-initiated and $\mathrm{OH}$-initiated oxidation conditions, with and without added $\mathrm{NO}_{\mathrm{x}}$, were used to prepare model SOA from VOC as shown in Table 1 and Table 2. VOC were used at their stated commercial purity (Table S1). All experiments were performed under dry conditions (relative humidity $<2 \%$ ) and in the absence of seed particles. The $\mathrm{O}_{3}$-initiated reactions were carried out in a $17 \mathrm{~L}$ flow tube reactor described by Bones et al. (2010). Liquid VOC was injected by a syringe pump at a rate of $25 \mu \mathrm{L} /$ hour into a 5 SLM (standard liters per minute) flow of zero air. A 0.5 SLM flow of oxygen (Airgas; 99.994\% purity) was 
sent through an ozone generator and a custom-made ozone photometric detector. The $\mathrm{O}_{3}$ - and VOC-containing flows were mixed at the entrance of the flow cell. Typical mixing ratios in the flow cell ranged from 60-100 ppm (parts per million by volume) of $\mathrm{O}_{3}$ and 10-30 ppm of VOC, respectively. Residence time in the flow tube was less than 5 minutes, but sufficient to oxidize most of the VOC and to form SOA. A 1-m charcoal denuder scrubbed the residual $\mathrm{O}_{3}$ and gas-phase organic compounds from the flow exiting the reactor. Multiple SOA collection methods were used in the experiments. In some experiments, SOA was collected by impaction on foil substrates using a multi-orifice uniform-deposit impactor (MOUDI, MSP model 110-R) sampling at 30 SLM. In other experiments, SOA was collected on stage D of a Sioutas impactor (Sioutas, 2004) modified to accept either a $\mathrm{CaF}_{2}$ window or foil substrates. The specified cut-off point of this impactor stage was $0.25 \mu \mathrm{m}$ at 9 SLM flow rate, but sampling was done at 15 SLM to drive the cut-off point to lower particle sizes. The foil substrates and $\mathrm{CaF}_{2}$ windows were weighed before and after SOA collection to determine the mass of SOA collected. In several experiments, SOA was collected on polytetrafluoroethylene (PTFE) filters (Millipore fluoropore, $0.2 \mu \mathrm{m}$ pore size). Absorption coefficients from SOA collected on foil substrates, $\mathrm{CaF}_{2}$ windows, and PTFE filters were comparable in magnitude. Depending on the yield of SOA, collection time for the flow tube was approximately 30 minutes to 2 hours. The samples were either analyzed immediately or sealed and frozen for later analysis.

The OH-initiated reactions were carried out in a $\sim 5 \mathrm{~m}^{3}$ Teflon chamber, equipped with UV-B lights (FS40T12/UVB, Solarc Systems Inc.) with emission centered at $310 \mathrm{~nm}$. The reactions took place under dry conditions (relative humidity $<2 \%$ ), in the absence of seed particles. Chamber experiments were carried out either under "high- $\mathrm{NO}_{\mathrm{x}}$ " oxidation conditions, with approximately $300 \mathrm{ppb}$ (parts per billion by volume) of NO added to the chamber to simulate an urban atmospheric environment, or "low- $\mathrm{NO}_{\mathrm{x}}$ " oxidation conditions, with no additional NO added to the chamber in order to simulate a remote atmospheric environment. For the $\mathrm{OH}$ precursor, $90 \mu \mathrm{L}$ of $\mathrm{H}_{2} \mathrm{O}_{2}$ (Aldrich; $30 \%$ by volume) was injected in the chamber by evaporation under a stream of zero air resulting in $\sim 4 \mathrm{ppm}$ of $\mathrm{H}_{2} \mathrm{O}_{2}$ vapor in the chamber. Precursor VOC was added to the chamber using the same method as was used for the $\mathrm{H}_{2} \mathrm{O}_{2}$ addition, with VOC concentrations in the chamber varying from $500 \mathrm{ppb}$ to 1 ppm. One exception was isoprene; we had to increase its starting mixing ratio to $4 \mathrm{ppm}$ in order to generate enough SOA for further analysis. The chamber content was mixed for several minutes using a fan, which was then turned off to minimize particle wall losses. The UV-B lamps were turned on for 1.5 to 4 hours to initiate photochemistry (see Table 1). SOA particle concentration within the chamber was monitored by a TSI model 3936 scanning mobility particle sizer (SMPS). A Thermo Scientific model 49i ozone analyzer recorded $\mathrm{O}_{3}$ data, while a Thermo Scientific model $42 \mathrm{i}-\mathrm{Y} \mathrm{NO}_{\mathrm{y}}$ analyzer recorded $\mathrm{NO} / \mathrm{NO}_{\mathrm{y}}$ data. SOA particles passed through an activated carbon denuder at approximately 15 SLM and were collected using PTFE filters. Collection times ranged from 2 to 3 hours, with approximately $100 \mu \mathrm{g}$ to $3500 \mu \mathrm{g}$ of SOA collected on the filter, depending on the sample. The amount of SOA on the filter was estimated from SMPS data, assuming an SOA particle density of 1.2 $\mathrm{g} / \mathrm{cm}^{3}$ and $100 \%$ collection efficiency by the filters. This assumed value of particle density represents an average of densities of anthropogenic and biogenic SOA materials reported by Hallquist et al. (2009). 
Table 1. Names and abbreviations for the VOC used to generate SOA samples in a smog chamber. The SOA samples are referred to using the code VOC/oxidation conditions; specifically, VOC/OH and $\mathrm{VOC} / \mathrm{OH} / \mathrm{NO}_{\mathrm{x}}$ refer to samples prepared under low- $\mathrm{NO}_{\mathrm{x}}$ and high- $\mathrm{NO}_{\mathrm{x}}$ conditions, respectively. The reaction time in the chamber is equivalent to the irradiation time.

\begin{tabular}{|l|c|c|c|c|c|c|}
\hline $\begin{array}{c}\text { Precursor } \\
\text { abbreviated } \\
\text { name) }\end{array}$ & Oxidant & $\begin{array}{c}\text { Initial } \\
\text { VOC } \\
(\mathrm{ppm})\end{array}$ & $\begin{array}{c}\text { Initial } \\
\mathrm{NO} \\
(\mathrm{ppb})\end{array}$ & $\begin{array}{c}\text { Reaction } \\
\text { time (h) }\end{array}$ & $\begin{array}{c}\text { Collection } \\
\text { time (h) }\end{array}$ & $\begin{array}{c}\text { Amount } \\
\text { typically } \\
\text { collected } \\
(\mathrm{mg})\end{array}$ \\
\hline $\begin{array}{l}\text { 2-Methylpyrrole } \\
(2 \mathrm{MPYR})\end{array}$ & $\mathrm{OH}$ & 0.5 & $<1$ & 3 & 2 & 1.3 \\
\hline 2MPYR & $\mathrm{OH} / \mathrm{NO}_{\mathrm{x}}$ & 0.5 & 300 & 2 & 3 & 1.8 \\
\hline$\alpha$-Pinene (APIN) & $\mathrm{OH} / \mathrm{NO}_{\mathrm{x}}$ & 0.5 & 300 & 2 & 3 & 2.3 \\
\hline Farnesene (FAR) & $\mathrm{OH}$ & 0.5 & $<1$ & 1.5 & 3 & 3.5 \\
\hline FAR & $\mathrm{OH} / \mathrm{NO}_{\mathrm{x}}$ & 0.5 & 300 & 1.5 & 3 & 3.0 \\
\hline Guaiacol (GUA) & $\mathrm{OH}$ & 0.5 & $<1$ & 2 & 3 & 0.95 \\
\hline GUA & $\mathrm{OH} / \mathrm{NO}_{\mathrm{x}}$ & 0.5 & 300 & 1 & 3 & 1.3 \\
\hline Isoprene (ISO) & $\mathrm{OH}$ & 4.0 & $<1$ & 4 & 2.5 & 0.10 \\
\hline Linalool (LIN) & $\mathrm{OH}$ & 0.5 & $<1$ & 2 & 3 & 1.5 \\
\hline LIN & $\mathrm{OH} / \mathrm{NO}_{\mathrm{x}}$ & 0.5 & 300 & 2 & 3 & 1.5 \\
\hline $\begin{array}{l}\text { Naphthalene } \\
\text { (NAP) }\end{array}$ & $\mathrm{OH}$ & 0.4 & $<1$ & 2 & 3 & 1.0 \\
\hline NAP & $\mathrm{OH} / \mathrm{NO}_{\mathrm{x}}$ & 0.4 & 400 & 2 & 3 & 1.0 \\
\hline Ocimene (OCI) & $\mathrm{OH}$ & 0.5 & $<1$ & 2 & 3 & 2.0 \\
\hline OCI & $\mathrm{OH} / \mathrm{NO}_{\mathrm{x}}$ & 0.5 & 300 & 2 & 3 & 1.2 \\
\hline Toluene (TOL) & $\mathrm{OH}$ & 1.0 & $<1$ & 3 & 3 & 1.3 \\
\hline TOL & $\mathrm{OH} / \mathrm{NO}_{\mathrm{x}}$ & 1.0 & 1000 & 3.5 & 4 & 0.70 \\
\hline p-Xylene (XYL) & $\mathrm{OH}$ & 1.0 & $<1$ & 3 & 3 & 0.60 \\
\hline XYL & $\mathrm{OH} / \mathrm{NO}_{\mathrm{x}}$ & 1.0 & 300 & 3 & 3 & 1.0 \\
\hline
\end{tabular}

Table 2. Names and abbreviations for the VOC used to generate flow tube ozonolysis SOA samples. The initial VOC concentration in flow tube experiments is the steady-state mixing ratio the VOC would have in the absence of ozone. Ozone was added in small excess with respect to the VOC. The flow tube residence time is on the order of minutes.

\begin{tabular}{|l|c|c|}
\hline \multicolumn{1}{|c|}{ Precursor } & Initial VOC $(\mathrm{ppm})$ & $\begin{array}{c}\text { Amount typically collected } \\
(\mathrm{mg})\end{array}$ \\
\hline 2MPYR & 20 & 0.80 \\
\hline APIN & 10 & 2.0 \\
\hline ISO & 10 & 0.15 \\
\hline 1-Methylpyrrole (1MPYR) & 20 & 0.20 \\
\hline Imidazole (IMID) & 30 & 0.20 \\
\hline$\beta$-Myrcene (BMYR) & 10 & 0.40 \\
\hline$\beta$-Pinene (BPIN) & 10 & 0.70 \\
\hline d-Limonene (LIM) & 10 & 7.3 \\
\hline
\end{tabular}


All of the samples were dissolved by vigorous shaking of the substrates immersed in 5 $\mathrm{mL}$ of water or methanol solvent for 10 to 15 minutes. Sonication was avoided to prevent formation of peroxides in the extract (Mutzel et al., 2013). Water was used as the extracting solvent in initial experiments, but not all SOA were found to be fully soluble in water (Romonosky et al., 2015; Updyke et al., 2012). Therefore, methanol was used as the extracting solvent for the remaining experiments. To determine the extraction efficiency using methanol, filters were extracted twice in two separate aliquots of solvent, and absorption spectra were taken using a UV/Vis spectrometer, as described below. From comparison of the recorded absorbance values, it was concluded that extraction efficiency in the first extraction step was greater than $80 \%$ in all cases. We did not correct for the incompletely extracted material and assumed that the first step extracted everything; this assumption introduces up to $20 \%$ uncertainty in the resulting absorption coefficients. Typical concentrations of SOA in the extract were $20-900 \mu \mathrm{g} / \mathrm{mL}$, which translates into $70-3000 \mu \mathrm{M}$, assuming an effective molecular weight of $300 \mathrm{~g} / \mathrm{mol}$ for the SOA compounds.

The SOA extracts were placed in a $1 \mathrm{~cm}$ quartz cuvette for absorption measurements. A dual beam spectrometer (Shimadzu UV-2450), with pure solvent as the reference, was used to take the UV/Vis absorption spectra. Wavelength-dependent mass absorption coefficients (MAC), in units of $\mathrm{cm}^{2} \mathrm{~g}^{-1}$, were calculated from the base-10 absorbance, $A_{10}$, of an SOA extract with the solution mass concentration, $C_{\text {mass }}\left(\mathrm{g} \mathrm{cm}^{-3}\right)$, and path length, $b(\mathrm{~cm})$ :

$$
\operatorname{MAC}(\lambda)=\frac{A_{10}^{\text {solution }}(\lambda) \times \ln (10)}{b \times C_{\text {mass }}}
$$

Note that the mass-normalized absorption coefficients of the bulk SOA material calculated in Eq. (1) should not be confused with the mass-normalized absorption cross sections of aerosolized particles (Laskin et al., 2015). In order to calculate $C_{\text {mass }}$ from the SMPS data we assumed an average density of $1.2 \mathrm{~g} / \mathrm{cm}^{3}$ for all the SOA samples we generated. A number of other values for the SOA densities have been reported (Hallquist et al., 2009). The following equation can be used to correct the MAC values reported in this work to the actual MAC values if a different SOA density is adopted:

$$
M A C_{\text {corrected }}(\lambda)=\frac{M A C_{\text {reported }}(\lambda) \times 1.2 \mathrm{~g} / \mathrm{cm}^{3}}{\rho_{\text {actual }}}
$$

where $\rho_{\text {actual }}$ refers to any other assumed or determined density. If $\rho_{\text {actual }}>1.2 \mathrm{~g} / \mathrm{cm}^{3}$, the resulting corrected MAC values would be smaller than the ones reported here, while $\rho_{\text {actual }}<$ $1.2 \mathrm{~g} / \mathrm{cm}^{3}$ would result in larger corrected MAC values. In either case we do not expect the adjustment to be larger than $20 \%$ based on the spread of the SOA densities listed in Hallquist et al. (2009). In combination with the $20 \%$ uncertainty for the completeness of SOA extraction, the overall accuracy of the reported MAC values should be on the order of $\pm 30 \%$. This is sufficient for the purpose of estimation of lifetimes done in this paper. 


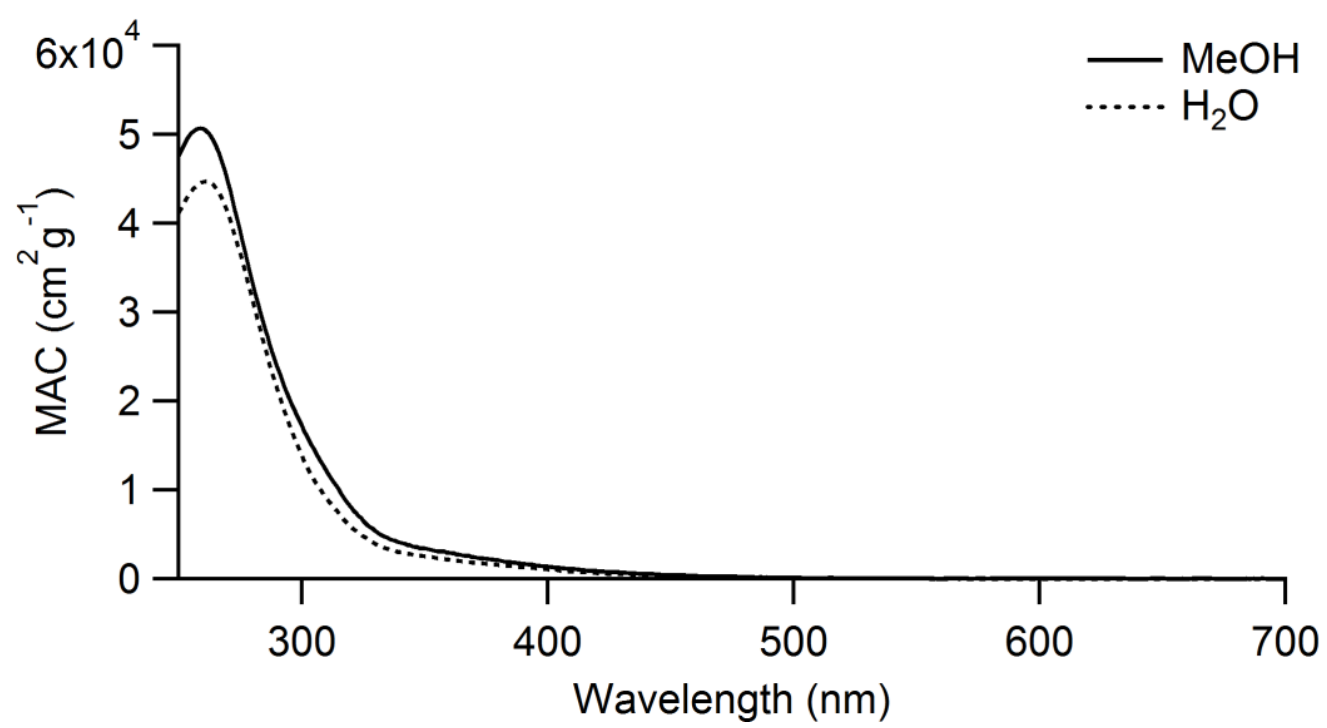

Figure 1. A comparison of $\mathrm{MAC}$ values for $1 \mathrm{MPYR} / \mathrm{O}_{3} \mathrm{SOA}$, extracted in either water or methanol.

For water-soluble SOA investigated in this study, the MAC values from the absorption spectra of methanol extracts and the water extracts were found to be comparable in magnitude, as seen in Figure 1. For SOA that was poorly soluble in water, the shape of the absorption spectrum in water and in methanol were similar, but the methanol spectrum had higher absorbance because it contained more dissolved material. In view of the small sensitivity of the shape of the spectrum to the extracting solvent, it is expected that the absorption spectra of SOA compounds are not too sensitive to the environment, and MAC calculated from Eq. (1) approximate MAC of bulk SOA material reasonably well.

Equation (1) is only valid in the low concentration limit in which the Beer-Lambert law is obeyed. The Supporting Information section contains examples of verification of linearity of the measured base-10 absorbance as a function of the mass concentration of SOA in the solution (Figs. S1-S3). Such absorbance linearity checks were carried out for all the SOA samples examined in this work, typically at $280 \mathrm{~nm}$, where all SOA had easily detectable absorbance. Because absorbance values of the SOA solutions were recorded at different SOA concentration levels, the MAC spectra were built from the absorbance data in a piecewise fashion, wherein the solutions with higher concentrations were used to get MAC at longer wavelengths, and solutions with lower concentration were used to get MAC at shorter wavelengths. This helped improve the signal-to-noise ratio in MAC at longer wavelengths without having to violate the Beer-Lambert law at shorter wavelengths.

\section{RESULTS AND DISCUSSION}

The MAC values for all the SOA samples prepared in this study are shown on a logarithmic scale in Fig. 2. The same figure also shows the MAC values on a linear scale for the SOA derived from APIN, ISO, and XYL; the corresponding plots for the rest of SOA can be found in figures S4-S29 of the supporting information section. The MAC spectra have characteristic shapes for absorption spectra of common organic molecules, with the peak of absorption occurring in the UV range and a tail of absorption in the near-UV and visible ranges. The MAC values for some of the SOA samples, especially the ones generated from 
ISO, appear noisy because of the low SOA mass yield resulting in low measured absorbance values for the SOA solutions. In agreement with the observations of Liu et al. (2015), the MAC values for the SOA from aromatic precursors (TOL, XYL, GUA, NAP) are roughly an order of magnitude higher than MAC values for the SOA from isoprene and terpenes. Surprisingly, high MAC values were observed for SOA derived from heteroaromatic precursors 1MPYR (Fig. S22) and 2MPYR (Figs. S23-S25). It was initially suspected that the presence of the heterocyclic nitrogen atoms in these compounds may contribute to the high absorption coefficients of their SOA; however, ozonolysis of IMID resulted in SOA with relatively low MAC values (Fig. S12). Clearly, the absorption spectra of SOA produced from nitrogen containing organics are highly sensitive to the structure of the VOC precursor.
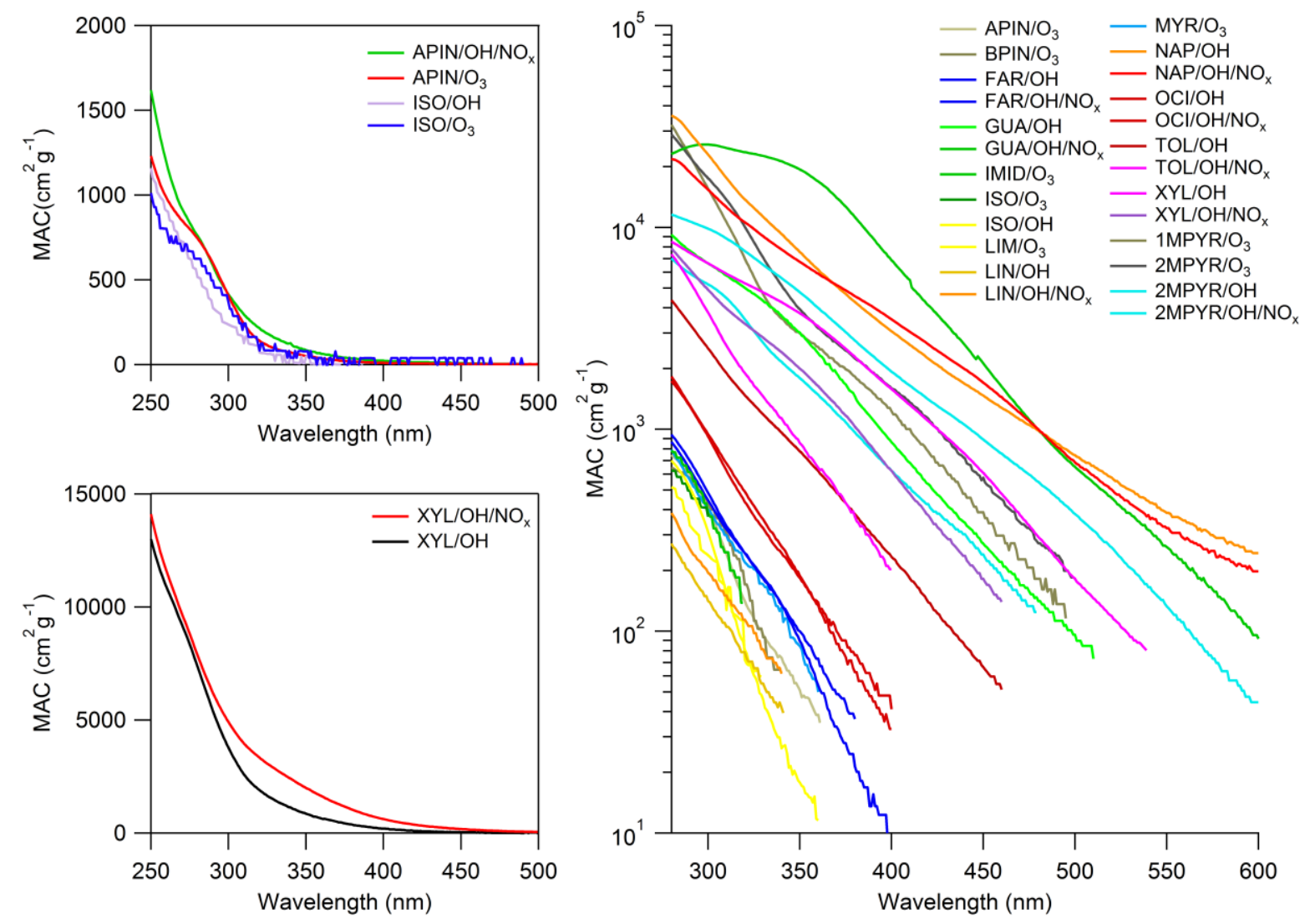

Figure 2. The measured MAC values for all the SOA on a logarithmic scale. Two left panels compare MAC values for XYL, APIN, and ISO SOA on a linear scale.

The rate constant of a photochemical reaction, $J$, for any compound in SOA can be calculated from

$$
J=\int \sigma(\lambda) \phi(\lambda) F(\lambda) d \lambda
$$

where $\sigma$ is the absorption cross-section $\left[\mathrm{cm}^{2} \operatorname{molec}^{-1}\right], \phi$ is the quantum yield for the process of interest, and $F$ is the spectral flux density [photon $\mathrm{cm}^{-2} \mathrm{~s}^{-1} \mathrm{~nm}^{-1}$ ]. Whereas the gas-phase absorption cross-sections and quantum yields are well known for a number of simple organic compounds (Sander et al., 2011), there is only limited information available for the multifunctional molecules found in SOA. Furthermore, significant matrix effects on absorption spectra and quantum yields can be expected in the highly-viscous environment 
inside the particles (Lignell et al., 2014). Another complication is that a complex environmental mixture, such as an organic aerosol, contains a broad spectrum of compounds with different photophysical and photochemical processes. Some of them do not measurably absorb radiation in the wavelength of interest. Others absorb the radiation, but can dissipate the energy without undergoing a reaction, i.e., through internal conversion. Only a certain fraction of the components of aerosol can undergo photolysis, photoisomerization, photoassociation and other photochemical reactions leading to a change in the aerosol composition.

In this work, a simplified approach was taken in which an effective photochemical rate constant is calculated from sample-averaged properties. This approach assumes that the composition of the SOA can be represented by an average formula with an effective molecular weight (MW), and that all of the SOA molecules have identical photophysical properties. The effective MW used for this study was $300 \mathrm{~g} / \mathrm{mol}$, as determined by averaging MWs from high-resolution mass spectra of broad range of SOA reported by Romonosky et al. (2015). The effective absorption cross section can then be estimated from MAC values (where $N_{A}$ is the Avogadro's constant).

$$
\sigma_{\text {effective }}(\lambda)=\frac{M A C_{\text {material }}(\lambda) \times M W}{N_{A}}
$$

The quantum yields for the photochemical reactions of SOA compounds inside the particles are not known. As a limiting case, unity quantum yield is assumed, characteristic of the photolysis of hydrogen peroxide (Sander et al., 2011). Specifically, a step-function wavelength dependence of the quantum yield is used, in which $\phi=1$ at all wavelengths below $\lambda_{0}=400 \mathrm{~nm}$, and $\phi=0$ above $\lambda_{0}$. The upper wavelength limit is introduced because the quantum yield can be expected to drop sharply below the dissociation threshold. For example, $\mathrm{NO}_{2}$ photolysis occurs with $\phi \sim 1$ below $398 \mathrm{~nm}$, and quantum yield declines rapidly above this threshold wavelength (Finlayson-Pitts and Pitts, 2000). Likewise, $\mathrm{O}_{3}$ has a high quantum yield below its dissociation threshold at $310 \mathrm{~nm}$, and it drops sharply above $310 \mathrm{~nm}$.

The assumption of the unity value may be unrealistic for condensed-phase photochemical processes; therefore, a model in which the quantum yield decreases with increasing wavelengths is also considered. The wavelength dependence of the quantum yield of acetone at $1 \mathrm{~atm}$ is adopted as a more realistic case. Specifically, acetone undergoes efficient photolysis only below $\sim 300 \mathrm{~nm}$, where the solar spectral flux is quite small, and is resilient to photolysis at longer wavelengths. Similar behavior is expected from condensedphase carbonyl compounds as well as other types of organic species. Figure 3 shows the assumed quantum yields for both the $\mathrm{H}_{2} \mathrm{O}_{2}$-like model and the acetone-like model. 


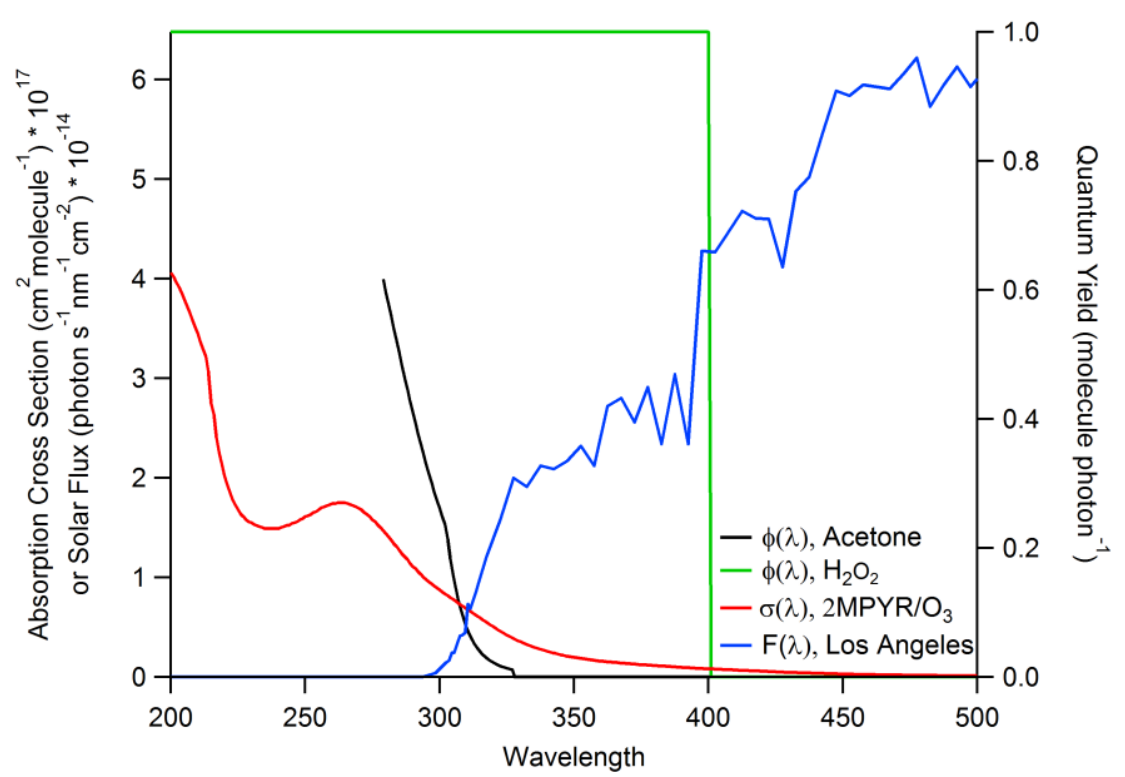

Figure 3. The wavelength dependence of quantum yields used in this work: the $\mathrm{H}_{2} \mathrm{O}_{2}$ model with unity quantum yield below $400 \mathrm{~nm}$ (green trace) and the quantum yields for the photolysis of acetone at $1 \mathrm{~atm}$ (black trace). These quantum yields were convoluted with the effective absorption cross sections (an example for $2 \mathrm{MPYR} / \mathrm{O}_{3}$ is shown in red trace) and solar spectral flux (an example at 13.00 hours in Los Angeles in June is shown in blue trace) to obtain the effective photochemical rate constants. The absorption cross sections and the flux were multiplied by factors of $10^{17}$ and $10^{-14}$, respectively, in order to show them in the same plot.

With these assumptions, the effective photochemical rate constants can be calculated for the solar-zenith-angle (SZA) dependent values of solar spectral flux, $F$.

$$
J_{\text {effective }}=\int \sigma_{\text {effective }}(\lambda) \phi(\lambda) F(\lambda, S Z A) d \lambda
$$

Figure 4 shows the resulting dependence of $\mathrm{J}$ on $\mathrm{SZA}$ for $2 \mathrm{MPYR} / \mathrm{O}_{3}$ (one of the more absorbing SOA in our data set) and ISO/OH (one the less absorbing SOA). The peak values of $\mathrm{J}$ range from $10^{-2}$ to $10^{-4} \mathrm{~s}^{-1}$ (when using the $\mathrm{H}_{2} \mathrm{O}_{2}$ model for the quantum yields), which represent fast processes in comparison to typical atmospheric reactions. Figure 5 shows the dependence of $\mathbf{J}$ on the time of day for Los Angeles (34 latitude) on June 22, 2014.

The effective lifetime for the photochemical change in SOA can be calculated as an inverse of the 24-hour average rate

$$
\tau=\left(\left\langle J_{\text {effective }}\right\rangle_{24 h r}\right)^{-1}
$$

The resulting values calculated from Eq. (6) for all the SOA types probed here for both the $\mathrm{H}_{2} \mathrm{O}_{2}$ and acetone models of quantum yields are summarized in Table 3. This table also lists the lifetimes during the peak irradiation in Los Angeles at 13:00 hours, which is more meaningful for compounds with very short lifetimes. 


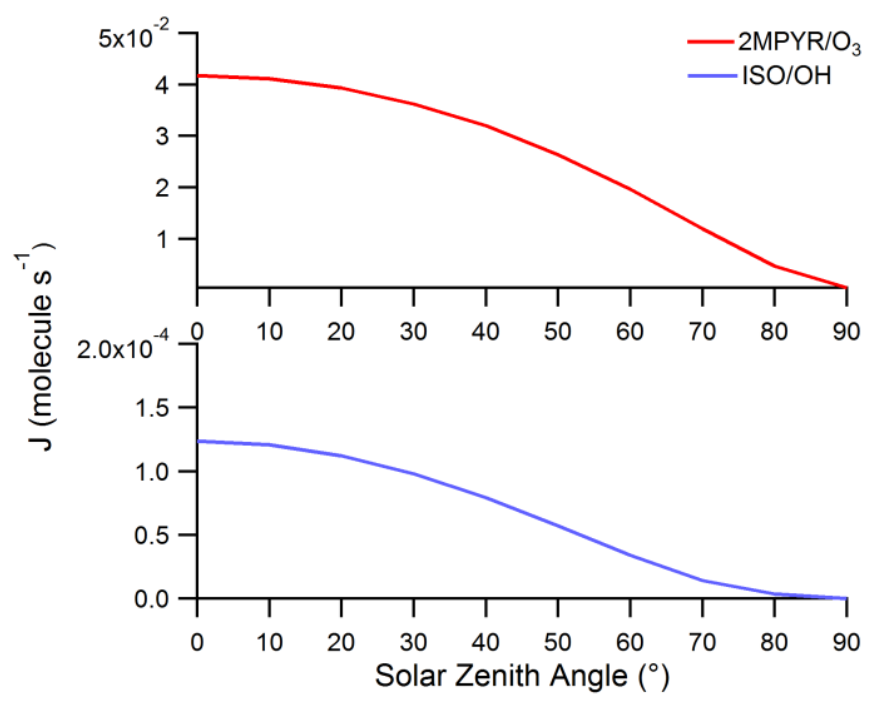

Figure 4. Photochemical rate constant, $J$, of $2 \mathrm{MPYR} / \mathrm{O}_{3} \mathrm{SOA}$ and ISO/OH SOA as a function of SZA calculated using Eq. (5) and assuming the $\mathrm{H}_{2} \mathrm{O}_{2}$ model for the quantum yields.

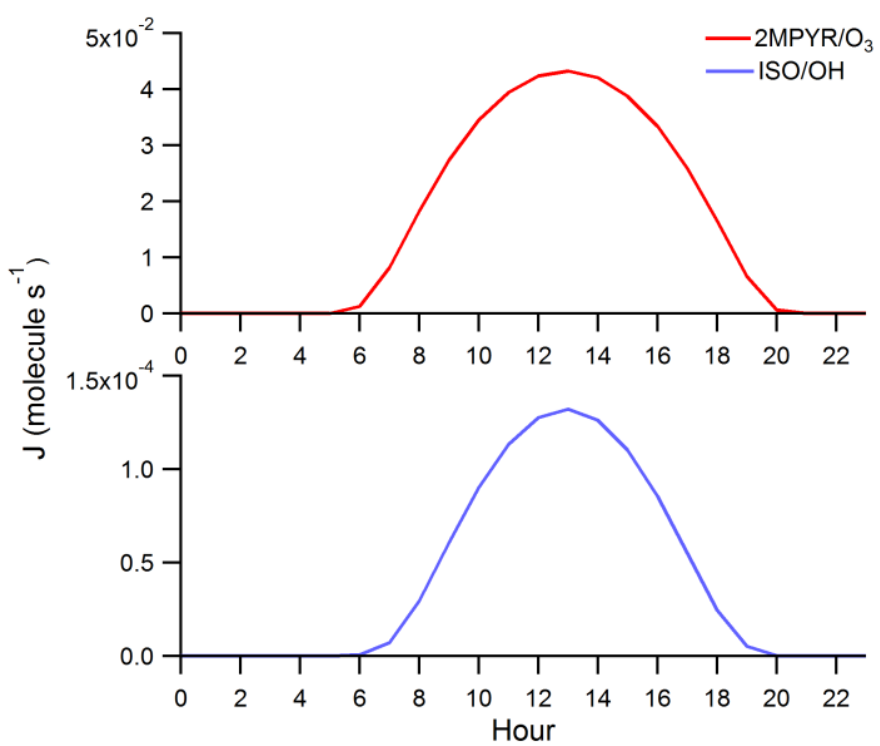

Figure 5. Photochemical rate constant, $J$, for the same SOA samples as used in Fig. 4 plotted as a function of time over a 24 hour period in Los Angeles ( $34^{\circ}$ latitude) on June 22, 2014. The 24-hour average values of $\langle\mathrm{J}\rangle$ are listed in Table 3 for all the SOA types probed in this work. 
Table 3. Effective SOA lifetimes with respect to photochemistry for Los Angeles.

\begin{tabular}{|c|c|c|c|c|}
\hline Sample & $\begin{array}{c}\text { Effective } \\
\text { Lifetime using } \\
\text { QY of } \mathrm{H}_{2} \mathrm{O}_{2} \\
(24 \mathrm{~h} \text { average) } \\
\text { (min) }\end{array}$ & $\begin{array}{c}\text { Peak Effective } \\
\text { Lifetime } \\
\text { using QY of } \\
\mathrm{H}_{2} \mathrm{O}_{2} \text { (min) }\end{array}$ & $\begin{array}{c}\text { Effective } \\
\text { Lifetime using } \\
\text { QY of acetone } \\
\text { (24 h average) } \\
\text { (min) }\end{array}$ & $\begin{array}{c}\text { Peak Effective } \\
\text { Lifetime } \\
\text { using QY of } \\
\text { acetone (min) }\end{array}$ \\
\hline $1 \mathrm{MPYR} / \mathrm{O}_{3}$ & 1.4 & 0.52 & 110 & 31 \\
\hline $2 \mathrm{MPYR} / \mathrm{O}_{3}$ & 1.0 & 0.39 & 85 & 24 \\
\hline 2MPYR/OH & 2.6 & 0.96 & 260 & 75 \\
\hline $2 \mathrm{MPYR} / \mathrm{OH} / \mathrm{NO}_{\mathrm{x}}$ & 1.0 & 0.38 & 130 & 37 \\
\hline APIN/ $\mathrm{O}_{3}$ & 85 & 30 & 4800 & 1300 \\
\hline $\mathrm{MYR} / \mathrm{O}_{3}$ & 58 & 21 & 3800 & 1100 \\
\hline $\mathrm{BPIN} / \mathrm{O}_{3}$ & 90 & 31 & 4000 & 1100 \\
\hline FAR/OH & 53 & 19 & 3500 & 1000 \\
\hline FAR/OH/NO & 47 & 17 & 3400 & 960 \\
\hline GUA/OH & 1.7 & 0.63 & 190 & 56 \\
\hline $\mathrm{IMID} / \mathrm{O}_{3}$ & 95 & 34 & 4800 & 1300 \\
\hline $\mathrm{ISO} / \mathrm{O}_{3}$ & 88 & 32 & 5400 & 1500 \\
\hline $\mathrm{ISO} / \mathrm{OH}$ & 410 & 130 & 7600 & 2100 \\
\hline $\mathrm{LIM} / \mathrm{O}_{3}$ & 230 & 77 & 7200 & 2000 \\
\hline $\mathrm{LIN} / \mathrm{OH} / \mathrm{NO}_{\mathrm{x}}$ & 100 & 37 & 7700 & 2200 \\
\hline LIN/OH & 160 & 56 & 11000 & 3100 \\
\hline $\mathrm{OCI} / \mathrm{OH}$ & 25 & 8.9 & 1700 & 480 \\
\hline $\mathrm{OCI} / \mathrm{OH} / \mathrm{NO}_{\mathrm{x}}$ & 25 & 9.1 & 1800 & 520 \\
\hline XYL/OH & 5.5 & 2.0 & 430 & 120 \\
\hline $\mathrm{XYL} / \mathrm{OH} / \mathrm{NO}_{\mathrm{x}}$ & 2.5 & 0.9 & 280 & 81 \\
\hline Toluene/OH & 6.2 & 2.3 & 590 & 170 \\
\hline Toluene/OH/NO & 1.3 & 0.50 & 190 & 58 \\
\hline Naphthalene/OH & 0.62 & 0.23 & 64 & 18 \\
\hline Naphthalene/OH/NO & 0.68 & 0.25 & 89 & 26 \\
\hline Catechol $/ \mathrm{O}_{3}{ }^{\mathrm{a}}$ & 3.0 & 1.1 & 260 & 75 \\
\hline $\begin{array}{l}\text { IEPOX/MgSO } \mathrm{Mg}_{4} \text { seed } \\
\text { particle/dry conditions }\end{array}$ & 6.4 & 2.3 & 540 & 154 \\
\hline
\end{tabular}

${ }^{a}$ The MAC data were obtained from Liu et al. (2013) and used in lifetime calculations.

${ }^{\mathrm{b}}$ The MAC data were obtained from Lin et al. (2014) and used in lifetime calculations.

The data in Table 3 reflect the high level of diversity in the optical properties of different types of biogenic and anthropogenic SOA. They also suggest that photochemical reactions in SOA can potentially occur on atmospherically meaningful time scales. Lifetime estimates for the SOA samples using the quantum yield of $\mathrm{H}_{2} \mathrm{O}_{2}$ are on the order of minutes, with the peak irradiation lifetimes being as short as a few seconds in some cases. These lifetimes are probably unrealistically short because it is unlikely that SOA compounds can photolyze with quantum yields approaching unity. The lifetime estimates relying on the quantum yield of acetone range from 60-11000 minutes (1-180 hours) and likely represent a more realistic estimate for the time scales of photochemical reactions occurring in aerosols. For example, the lifetime predicted for $\mathrm{APIN} / \mathrm{O}_{3} \mathrm{SOA}$ with the acetone model for quantum yields (4800 min or 3.3 days) is of the same order of magnitude as the lifetime for the photolysis-induced loss of peroxides from $\mathrm{APIN} / \mathrm{O}_{3} \mathrm{SOA}$ ( $\sim 10$ days) measured by Epstein et 
al. (2014). It is noted that a direct comparison is complicated in this case by the possible photochemical recycling of peroxides in the particles in the Epstein et al. (2014) experiments. The predicted average lifetimes of 60-90 $\mathrm{hr}$ for NAP SOA (with the acetone model for quantum yields) are also in fair agreement with the observed lifetimes for photobleaching of NAP SOA solutions in water, which ranged from 15 to $90 \mathrm{hr}$ depending on the observation wavelength (Lee et al., 2014). Assuming that molecules in SOA can undergo photochemistry with photolysis quantum yields similar to that of acetone, condensed-phase photochemistry can become competitive with the more traditional mechanisms of SOA aging, such as multiphase oxidation by $\mathrm{OH}$. This is the most important conclusion of this work.

The SOA examined in this work was prepared under dry conditions and without using seed particles because we wanted to minimize contributions from the seed particle material to the measured absorption coefficients of the organic material in SOA. While neutral seed particles, such as ammonium sulfate, are not expected to affect the optical absorption properties of the SOA material, highly-acidic seed particles may affect both the mechanism of SOA production (Czoschke et al., 2003) and the optical absorption properties (Nozière and Esteve, 2007; Song et al., 2013; Van Wyngarden et al., 2015) of SOA. For example, Lin et al. (2014) found that SOA formed by uptake of isoprene epoxydiol (IEPOX) onto acidic particles was considerably more absorbing than that SOA formed on neutralized seed particles. To test for the effect of the seed particle acidity, we have included the IEPOX/acidic seed data from Lin et al. (2014) in Table 3. The estimated lifetime of the IEPOX/acidic seed SOA is more than an order of magnitude shorter than that for IOS/OH or $\mathrm{ISO} / \mathrm{O}_{3}$ SOA. Clearly, the effect of the aerosol seed acidity and the coupled effect of the relative humidity on the optical absorption properties of SOA are significant and deserve further study.

Tables 1 and 2 indicate that that amount of collected SOA material was typically between 0.2 and up to $3.5 \mathrm{mg}$. The large amount of SOA material was necessary for the accurate measurement of absorption coefficients. The high material requirements of these experiments necessitated using unrealistically high concentrations of VOC precursors, especially in the case of isoprene, and for all flow tube experiments. Future experiments should address the question whether the MAC values are strongly dependent on the VOC concentration used in the SOA preparation.

While our analysis predicts that condensed-phase photochemistry in SOA may be reasonably fast under typical atmospheric conditions, it does not say anything about the effect of these photochemical reactions on the climate- and health-related properties of aerosols, such as their mass concentration, average particle size, absorption coefficient, toxicity, etc. This effect will, of course, depend on the prevailing type of photochemistry occurring in SOA particles. For example, in the SOA derived from monoterpenes and isoprene, photolysis of peroxide and carbonyl functional groups can be expected to fragment SOA compounds into smaller molecules (Romonosky et al., 2015), which may then evaporate from particles to gaseous phase as observed in several previous experiments with bulk SOA samples (Hung et al., 2013; Mang et al., 2008; Walser et al., 2007). The evaporation will lead to SOA particle shrinking, as observed, for example in experiments by Epstein et al. (2014) and Wong et al. (2014) with APIN/O 3 SOA. However, it should not be assumed that fragmentation is always going to be the dominant photochemical pathway. For example, cis-pinonic acid, a major 
product of ozonolysis of APIN, undergoes a reasonably efficient photoisomerization into limononic acid, a structural isomer of cis-pinonic acid (Lignell et al., 2013). For the cases when photoisomerization is the dominant photochemical process, there should not be any effect on the particle size or mass concentration. Photoassociation reactions, in which two SOA compounds dimerize after absorbing a photon, will produce larger products than the initial reactants. This will have an effect of reducing the volatility of SOA compounds making the aerosol less likely to evaporate upon dilution. An even more interesting scenario is conceivable in which a photoexcited species on the particle surface reacts with a nearby VOC producing less volatile products and leads to an increase in the particle mass, as observed in recent laboratory experiments with aerosols containing photosensitizers (Aregahegn et al., 2013; Monge et al., 2012). In summary, condensed-phase photochemistry can either decrease or increase the particle mass and size depending on the nature of the dominant photochemical processes.

The effect of condensed-phase photochemistry on the optical properties of SOA is also very important because it has direct consequences for the radiative forcing by aerosols (Laskin et al., 2015). Light-absorbing SOA can lose or gain their chromophoric species as a result of various photochemical reactions. For example, recent laboratory experiments demonstrated that the wavelength dependence of the absorption coefficient can be dramatically altered by UV irradiation of several types of model brown carbon compounds (Lee et al., 2014; Rincon et al., 2010; Sareen et al., 2013; Zhao et al., 2015; Zhong and Jang, 2014). Such changes in the absorption coefficient of SOA are also important for gas-phase photochemistry because aerosols are capable of screening UV radiation and reducing ozone production in heavily polluted areas (Finlayson-Pitts and Pitts, 2000). Clearly, more work is needed to explore the rate and occurrence of such photochemical effects on the SOA absorption spectra before these effects can be incorporated in climate and air pollution models.

\section{CONCLUSIONS}

The optical properties of SOA representative of biogenic and anthropogenic atmospheric environments were examined by making model SOA in a chamber or a flow tube and measuring their bulk mass absorption coefficients (MAC). This information was used to estimate the effective absorption cross sections of SOA and lifetimes of SOA compounds with respect to possible condensed-phase photochemical reactions. The calculated lifetimes suggest that condensed-phase photochemistry may potentially compete with other known aerosol aging processes. These findings have important implications for understanding the aging of atmospheric aerosols, and the potential effect of this photochemical aging on climate- and health-related properties of SOA.

\section{ACKNOWLEDGEMENTS}

The authors acknowledge support by the US National Science Foundation (NSF) grant AGS1227579. DR thanks NSF for the support via the Graduate Research Fellowship Program. PA thanks the Ford Foundation Predoctoral Fellowship Program of the National Academy of 
Science for their support. NA and MS thank Undergraduate Research Opportunities Program at the University of California, Irvine for support. The authors thank Dr. Jason Surratt and Dr. Ying-Hsuan Lin for providing tabular data for MAC values published in Lin et al. (2014).

\section{REFERENCES}

Aregahegn, K.Z., Nozière, B., George, C., 2013. Organic aerosol formation photo-enhanced by the formation of secondary photosensitizers in aerosols. Faraday Discuss. 165, 123-134.

Bateman, A.P., Nizkorodov, S.A., Laskin, J., Laskin, A., 2011. Photolytic processing of secondary organic aerosols dissolved in cloud droplets. Phys. Chem. Chem. Phys. 13, 1219912212.

Bones, D.L., Henrickson, D.K., Mang, S.A., Gonsior, M., Bateman, A.P., Nguyen, T.B., Cooper, W.J., Nizkorodov, S.A., 2010. Appearence of strong absorbers and fluorophores in limonene-o3 secondary organic aerosol due to $\mathrm{NH} 4+$ mediated chemical aging over long time scales. J. Geophys. Res. D 115, D05203.

Czoschke, N.M., Jang, M., Kamens, R.M., 2003. Effect of acidic seed on biogenic secondary organic aerosol growth. Atmos. Environ. 37, 4287-4299.

Epstein, S.A., Blair, S.L., Nizkorodov, S.A., 2014. Direct photolysis of $\alpha$-pinene ozonolysis secondary organic aerosol: Effect on particle mass and peroxide content. Environ. Sci. Technol. 48, 11251-11258.

Ervens, B., Turpin, B., Weber, R., 2011. Secondary organic aerosol formation in cloud droplets and aqueous particles (aqSOA): A review of laboratory, field and model studies. Atmos. Chem. Phys. 11, 11069-11102.

Finlayson-Pitts, B.J., Pitts, J.N., 2000. Chemistry of the upper and lower atmosphere: Theory, experiments, and applications. Academic Press, San Diego.

George, C., Ammann, M., D’Anna, B., Donaldson, D.J., Nizkorodov, S.A., 2015. Heterogeneous photochemistry in the atmosphere. Chem. Rev. 115, 4218-4258.

Geron, C., Rasmussen, R., Arnts, R.R., Guenther, A., 2000. A review and synthesis of monoterpene speciation from forests in the United States. Atmos. Environ. 34, 1761-1781.

Hallquist, M., Wenger, J.C., Baltensperger, U., Rudich, Y., Simpson, D., Claeys, M., Dommen, J., Donahue, N.M., George, C., Goldstein, A.H., Hamilton, J.F., Herrmann, H., Hoffmann, T., Iinuma, Y., Jang, M., Jenkin, M.E., Jimenez, J.L., Kiendler-Scharr, A., Maenhaut, W., McFiggans, G., Mentel, T.F., Monod, A., Prevot, A.S.H., Seinfeld, J.H., Surratt, J.D., Szmigielski, R., Wildt, J., 2009. The formation, properties and impact of secondary organic aerosol: Current and emerging issues. Atmos. Chem. Phys. 9, 5155-5236.

Hung, H.-M., Chen, Y.-Q., Martin, S.T., 2013. Reactive aging of films of secondary organic material studied by infrared spectroscopy. J. Phys. Chem. A 117, 108-116.

Kourtchev, I., Doussin, J.F., Giorio, C., Mahon, B., Wilson, E.M., Maurin, N., Pangui, E., Venables, D.S., Wenger, J.C., Kalberer, M., 2015. Molecular composition of aged secondary organic aerosol generated from a mixture of biogenic volatile compounds using ultrahigh resolution mass spectrometry. Atmos. Chem. Phys. Discuss. 15, 5359-5389.

Kroll, J.H., Ng, N.L., Murphy, S.M., Flagan, R.C., Seinfeld, J.H., 2006. Secondary organic aerosol formation from isoprene photooxidation. Environ. Sci. Technol. 40, 1869-1877.

Laskin, A., Laskin, J., Nizkorodov, S.A., 2015. Chemistry of atmospheric brown carbon. Chem. Rev. 115, 4435-4385.

Lee, H.J., Aiona, P.K., Laskin, A., Laskin, J., Nizkorodov, S.A., 2014. Effect of solar radiation on the optical properties and molecular composition of laboratory proxies of atmospheric brown carbon. Environ. Sci. Technol. 48, 10217-10226. 
Lignell, H., Epstein, S.A., Marvin, M.R., Shemesh, D., Gerber, B., Nizkorodov, S., 2013. Experimental and theoretical study of aqueous cis-pinonic acid photolysis. J. Phys. Chem. A $117,12930-12945$.

Lignell, H., Hinks, M.L., Nizkorodov, S.A., 2014. Exploring matrix effects on photochemistry of organic aerosols. Proc. Natl. Acad. Sci. U.S.A. 111, 13780-13785.

Lin, Y.-H., Budisulistiorini, S.H., Chu, K., Siejack, R.A., Zhang, H., Riva, M., Zhang, Z., Gold, A., Kautzman, K.E., Surratt, J.D., 2014. Light-absorbing oligomer formation in secondary organic aerosol from reactive uptake of isoprene epoxydiols. Environ. Sci. Technol. 48, 12012-12021.

Liu, P., Abdelmalki, N., Hung, H.-M., Wang, Y., Brune, W., Martin, S., 2015. Ultraviolet and visible complex refractive indices of secondary organic material produced by photooxidation of the aromatic compounds toluene and m-xylene. Atmos. Chem. Phys. 15, 1435-1446.

Liu, P., Zhang, Y., Martin, S.T., 2013. Complex refractive indices of thin films of secondary organic materials by spectroscopic ellipsometry from 220 to $1200 \mathrm{~nm}$. Environ. Sci. Technol. 47, 13594-13601.

Mang, S.A., Henricksen, D.K., Bateman, A.P., Andersen, M.P.S., Blake, D.R., Nizkorodov, S.A., 2008. Contribution of carbonyl photochemistry to aging of atmospheric secondary organic aerosol. J. Phys. Chem. A 112, 8337-8344.

Monge, M.E., Rosenørn, T., Favez, O., Müller, M., Adler, G., Riziq, A.A., Rudich, Y., Herrmann, H., George, C., D’Anna, B., 2012. Alternative pathway for atmospheric particles growth. Proc. Natl. Acad. Sci. U.S.A. 109, 6840-6844.

Mutzel, A., Rodigast, M., Iinuma, Y., Böge, O., Herrmann, H., 2013. An improved method for the quantification of SOA bound peroxides. Atmos. Environ. 67, 365-369.

Nguyen, T.B., Laskin, A., Laskin, J., Nizkorodov, S.A., 2012. Direct aqueous photochemistry of isoprene high-NOx secondary organic aerosol. Phys. Chem. Chem. Phys. 14, 9702-9714.

Nozière, B., Esteve, W., 2007. Light-absorbing aldol condensation products in acidic aerosols: Spectra, kinetics, and contribution to the absorption index. Atmos. Environ. 41, 1150-1163.

Pan, X., Underwood, J.S., Xing, J.H., Mang, S.A., Nizkorodov, S.A., 2009. Photodegradation of secondary organic aerosol generated from limonene oxidation by ozone studied with chemical ionization mass spectrometry. Atmos. Chem. Phys. 9, 3851-3865.

Presto, A.A., Huff Hartz, K.E., Donahue, N.M., 2005. Secondary organic aerosol production from terpene ozonolysis. 1. Effect of UV radiation. Environ. Sci. Technol. 39, 7036-7045.

Rincon, A.G., Guzman, M.I., Hoffmann, M.R., Colussi, A.J., 2010. Thermochromism of model organic aerosol matter. J. Phys. Chem. Lett. 1, 368-373.

Romonosky, D.E., Laskin, A., Laskin, J., Nizkorodov, S.A., 2015. High-resolution mass spectrometry and molecular characterization of aqueous photochemistry products of common types of secondary organic aerosols. J. Phys. Chem. A 119, 2594-2606.

Sander, S.P., Abbatt, J.P., Barker, J., Burkholder, J., Friedl, R., Golden, D., Huie, R., Kolb, C., Kurylo, M., Moortgat, G., Orkin, V., Wine, P., 2011. Chemical kinetics and photochemical data for use in atmospheric studies, evaluation no. 17. JPL Publication 10-6, Jet Propulsion Laboratory, Pasadena.

Sareen, N., Moussa, S.G., McNeill, V.F., 2013. Photochemical aging of light-absorbing secondary organic aerosol material. J. Phys. Chem. A 117, 2987-2996.

Sareen, N., Schwier, A.N., Shapiro, E.L., Mitroo, D., McNeill, V.F., 2010. Secondary organic material formed by methylglyoxal in aqueous aerosol mimics. Atmos. Chem. Phys. 10, 9971016.

Sioutas, C., 2004, Sioutas cascade impactor; University of Southern California: Patent US 6786105 B1 
Solomon, S., Qin, D., Manning, M., Chen, Z., Marquis, M., Averyt, K.B., Tignor, M., Miller, H.L., 2007. Climate change 2007: The physical sciene basis. Contribution of working group I to the fourth assessment report of the Intergovernmental Panel on Climate Change. IPPC:2007.

Song, C., Gyawali, M., Zaveri, R.A., Shilling, J.E., Arnott, W.P., 2013. Light absorption by secondary organic aerosol from $\alpha$-pinene: Effects of oxidants, seed aerosol acidity, and relative humidity. Journal of Geophysical Research: Atmospheres 118, 11,741-711,749.

Surratt, J.D., Murphy, S.M., Kroll, J.H., Ng, N.L., Hildebrandt, L., Sorooshian, A., Szmigielski, R., Vermeylen, R., Maenhaut, W., Claeys, M., Flagan, R.C., Seinfeld, J.H., 2006. Chemical composition of secondary organic aerosol formed from the photooxidation of isoprene. J. Phys. Chem. A 110, 9665-9690.

Updyke, K.M., Nguyen, T.B., Nizkorodov, S.A., 2012. Formation of brown carbon via reactions of ammonia with secondary organic aerosols from biogenic and anthropogenic precursors. Atmos. Environ. 63, 22-31.

Van Wyngarden, A., Pérez-Montaño, S., Bui, J., Li, E., Nelson, T., Ha, K., Leong, L., Iraci, L., 2015. Complex chemical composition of colored surface films formed from reactions of propanal in sulfuric acid at upper troposphere/lower stratosphere aerosol acidities. Atmos. Chem. Phys. 15, 4225-4239.

Walser, M.L., Park, J., Gomez, A.L., Russell, A.R., Nizkorodov, S.A., 2007. Photochemical aging of secondary organic aerosol particles generated from the oxidation of d-limonene. J. Phys. Chem. A 111, 1907-1913.

Wong, J.P., Zhou, S., Abbatt, J.P., 2014. Changes in secondary organic aerosol composition and mass due to photolysis: Relative humidity dependence. J. Phys. Chem. A 119, 43094316.

World Health, O., 1989. Indoor air quality: Organic pollutants. Environ. Technol. Lett. 10, 855-858.

Zhao, R., Lee, A.K.Y., Huang, L., Li, X., Yang, F., Abbatt, J.P.D., 2015. Photochemical processing of aqueous atmospheric brown carbon. Atmos. Chem. Phys. Discuss. 15, 29572996.

Zhong, M., Jang, M., 2014. Dynamic light absorption of biomass-burning organic carbon photochemically aged under natural sunlight. Atmos. Chem. Phys. 14, 1517-1525. 